INTIQAD: JURNAL AGAMA DAN PENDIDIKAN ISLAM

ISSN 1979-9950 (print) || ISSN 2598-0033 (online), http://jurnal.umsu.ac.id/index.php/intiqad

DOI: 10.30596/intiqad.v12i2.5197

Vol. 12, No. 2 (December 2020)

\title{
Ilmu dan Guru di Zaman Nabi Muhammad SAW
}

\author{
Wagiman Manik ${ }^{1 *}$ \\ STAI As-Sunnah Deli Serdang Sumut*1 \\ *1email:wagimanmanik85@gmail.com
}

\begin{abstract}
Islam is built on knowledge and charity, without knowledge a charity will not be acceptable and it could be that the practice is invalid. Therefore, Islam requires all adherents and adherents, both men and women to study. In addition to being an obligation, it is an obligation to seek knowledge, it turns out that Islam provides and prepares great rewards for those who are diligent and sincere in pursuing this knowledge. The virtue of knowledge and experts is very clear in this glorious Islamic religion, that knowledge is the cause of the easy path for a person to go to heaven.

Truly all the friends ra are teachers, because this noble religion came to us thanks to their tenacity and sincerity in conveying and teaching Islam to humans. The companions of the Prophet Muhammad are the best teachers in Islam after the Prophet Muhammad, because they have very good, praiseworthy and noble traits, character and characteristics. Therefore, every Muslim and Muslim educator should be able to follow, imitate and emulate the characteristics in their daily educational activities, even though sometimes there are some educators who are unable to make it happen optimally, but of course they still have to try their hardest to emulate the characteristics of these friends.
\end{abstract}

Keywords: Knowledge, Teacher, Age Prophet Muhammad SAW.

\section{Artikel Info}

Received:

28 August 2020

Revised:

20 September 2020

Accepted:

02 November 2020

Published:

03 December 2020

\section{Abstrak}

Islam dibangun di atas ilmu dan amal, tanpa ilmu maka suatu amal tidak akan berterima dan bisa jadi amalan tersebut tidak sah. Oleh karena itu Islam mewajibkan kepada semua pemeluk dan penganutnya baik laki-laki maupun wanita untuk menuntut ilmu. Menuntut ilmu di samping ia merupakan sebuah kewajiban, ternyata Islam menyediakan dan mempersiapkan pahala yang besar bagi mereka-mereka yang tekun dan ikhlas dalam menuntut ilmu tersebut. Keutamaan ilmu dan ahli ilmu sangat jelas di dalam agama Islam yang mulia ini, bahwa ilmu menjadi penyebab 
mudahnya jalan sesorang untuk menuju surga.

Sesungguhnya semua para sahabat ra adalah guru, karena agama yang mulia ini sampai kepada kita berkat kegigihan dan kesugguhan mereka dalam menyampaikan dan mengajarkan Islam kepada manusia. Para sahabat nabi Muhammad SAW adalah guru terbaik di dalam Islam setelah nabi Muhammad SAW., karena memang mereka memiliki sifat, watak dan karateristik yang sangat baik, terpuji dan mulia. Oleh karena itu setiap pendidik muslim dan muslimah hendaknya dapat mengikuti, mencontohi dan meneladani karakteristik dalam aktivitas mendidik mereka sehari-hari, walaupun terkadang ada sebagian pendidik tidak mampu untuk merealisasikannya secara maksimal, namun tentunya tetap harus berusaha sekuat tenaga untuk meneledani karakteristik para sahabat tersebut.

Kata Kunci: Ilmu, Guru, Zaman Nabi Muhammad SAW.

\section{A. Pendahuluan}

Penghulu para al-Anbiya' wal Mursalin Muhammad SAW telah meletakkan dasar-dasar pendidikan Islam berdasarkan petunjuk dari Rabbul 'Alamin yang telah menciptakan langit dan bumi ini, dan apa yang ada di antara keduanya, agar menjadi pedoman umat manusia yang ada pada masa itu dan umat yang akan datang setelah beliau SAW., oleh karena itu umat Islam harus ada pada diri mereka keinginan dan kemauan yang tinggi dan kuat untuk selalu menggali dan mempelajari dasardasar pendidikan yang telah beliau SAW praktikkan, ajarkan dan yang telah beliau SAW lakukan.
Para sahabat Nabi Muhammad SAW yang mendapatkan pendidikan langsung dari beliau memiliki kegigihan dan semangat yang tinggi dalam mempelajari dinul Islam dari Rasulullah SAW sekalipun banyak halangan dan rintangan yang mereka hadapi, baik dari keluarga mereka sendiri maupun dari orang lain, sehingga ada yang dihina, disiksa bahkan ada yang dibunuh, namun semua ini tidak menyurutkan dan mengurangi semangat dan kegigihan mereka dalam menjalani pendidikan yang dilakukan oleh Nabi Muhammad SAW baik di kediaman al-Arqam ibn Abi al-Arqam ra atau tempat yang lainnya, memang harus diakui bahwa masa-masa sulit yang dihadapi oleh para 
INTIQAD: JURNAL AGAMA DAN PENDIDIKAN ISLAM

ISSN 1979-9950 (print) || ISSN 2598-0033 (online), http://jurnal.umsu.ac.id/index.php/intiqad

DOI: 10.30596/intiqad.v12i2.5197

Vol. 12, No. 2 (December 2020)

sahabat ra yang merupakan benar. Pernyataannya harus dibuktikan pendidik/guru pertama setelah dengan melaksanakan konsekuensi dari

Rasulullah SAW terhadap ummat Islam ini dapat mereka lalui dengan baik, dan setelah itu merekapun bergerak maju terus untuk mendidik manusia yang datang setelah mereka.

Para pendidik adalah penjagapenjaga benteng di garis depan, pendidik generasi, penyiram tanaman, dan pemakmur lembaga-lembaga pendidikan, mereka berhak meraih pahala jihad, ucapan syukur dari para hamba dan pahala dari Allah SWT pada hari kiamat (Muhammad bin Ibrahim, 2002), oleh karena itu seorang guru merupakan komponen pendidikan yang sangat penting dalam kegiatan belajar mengajar. Kedudukan guru merupakan posisi yang penting dalam dunia pendidikan khususnya di lembaga pendidikan formal, karena mereka merupakan agen perubahan bagi sebuah bangsa dan negara untuk menuju ke arah yang lebih baik.

\section{B. Pembahasan}

Setiap muslim tidaklah cukup hanya dengan menyatakan keislamannya tanpa berusaha untuk memahami Islam dan Islam. Dan untuk melaksanakan konsekuensi-konsekuensi dari pengakuan bahwa kita sudah berIslam, dan berIslam itu membutuhkan ilmu yang terambil dari Al-Qu'ran dan Sunnah dengan mengikuti pemahaman para sahabat ra.

\section{Menuntut Ilmu Itu Wajib}

Rasulullah shallallahu 'alaihi wa sallam bersabda:

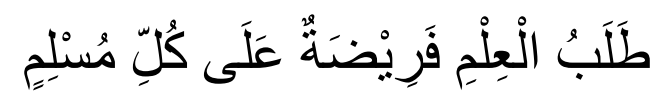

"Menuntut ilmu itu wajib atas setiap Muslim” (Ibnu Majah, tt).

Menuntut ilmu itu wajib bagi Muslim maupun Muslimah. Ketika sudah turun perintah Allah SWT. yang mewajibkan suatu hal, maka sebagai seorang muslim ia harus mengatakan sami'na wa atha'na, kami dengar dan kami taat, sesuai dengan firman Allah $T a$ 'ala:

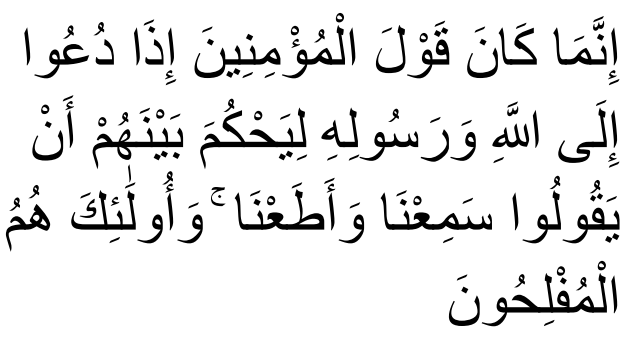
mengamalkannya dengan baik dan 
INTIQAD: JURNAL AGAMA DAN PENDIDIKAN ISLAM

ISSN 1979-9950 (print) || ISSN 2598-0033 (online), http://jurnal.umsu.ac.id/index.php/intiqad

DOI: 10.30596/intiqad.v12i2.5197

Vol. 12, No. 2 (December 2020)

Sesungguhnya ucapan orang-orang yang beriman apabila diajak untuk kembali kepada Allah dan Rasul-Nya agar Rasul itu memberikan keputusan hukum di antara mereka hanyalah dengan mengatakan, "Kami mendengar dan kami taat". Dan hanya merekalah orang-orang yang berbahagia (Q.S. AnNur, 24:51).

Sebagaimana seorang muslim dan muslimah meluangkan waktunya untuk shalat, ketika waktu sudah menunjukkan waktu shalat pasti ia akan meluangkan waktunya untuk shalat meskipun ia sedang bekerja, dan pekerjaannya itu masih banyak, seorang muslim dan muslimah akan tetap meninggalkan aktivitasnya dan segera mengerjakan shalat, maka begitu pula dengan menuntut ilmu, harus dicari dan kejar oleh seorang muslim dan muslimah.

Ilmu merupkan kunci segala kebaikan, karena ia merupakan sarana untuk menunaikan apa yang Allah SWT wajibkan kepada setiap muslim dan muslimah, keimanan tak akan sempurna, begitu juga dengan amal kecuali dengan ilmu, dengan ilmu itu Allah SWT disembah, dan dengan ilmu pula hak Allah SWT ditunaikan, dan dengan ilmu pula agama Allah SWT itu disebarkan.

Kebutuhan seseorang terhadap ilmu lebih besar dibandingkan kebutuhannya pada makanan dan minuman, sebab kelestarian urusan agama dan dunia bergantung pada ilmu. Al-Imam Ahmad mengatakan, "Manusia lebih memerlukan ilmu daripada makanan dan minuman, karena makanan dan minuman hanya dibutuhkan dua atau tiga kali sehari, sedangkan ilmu diperlukan di setiap waktu, jika kita ingin menyandang kehormatan luhur, kemuliaan yang tak terkikis oleh perjalanan malam dan siang, tak lekang oleh pergantian masa dan tahun, kewibawaan tanpa kekuasaan, kekayaan tanpa harta, kedigdayaan tanpa senjata, kebangsawanan tanpa keluarga besar, para pendukung tanpa upah, pasukan tanpa gaji, maka kita mesti berilmu.

Namun, yang dimaksud dengan kata ilmu di sini adalah ilmu syar'i, yaitu ilmu yang akan menjadikan seorang mukallaf mengetahui kewajibannya berupa masalah-masalah ibadah dan muamalah, juga ilmu tentang Allah SWT dan sifat-sifat-Nya, hak apa saja yang harus dia tunaikan dalam beribadah kepadaNya, dan mensucikanNya dari berbagai kekurangan (As-Syafi'I, 1957).

Dari penjelasan Ibnu Hajar rahimahullah di atas, jelaslah bawa ketika hanya disebutkan kata "ilmu" 
ISSN 1979-9950 (print) || ISSN 2598-0033 (online), http://jurnal.umsu.ac.id/index.php/intiqad

DOI: 10.30596/intiqad.v12i2.5197

Vol. 12, No. 2 (December 2020)

saja, maka yang dimaksud adalah ilmu syar'i. Oleh karena itu, merupakan sebuah kesalahan sebagian orang yang membawakan dalil-dalil tentang kewajiban dan keutamaan menuntut ilmu dari Al-Qur'an dan As-Sunnah.

Akan tetapi yang mereka maksud adalah untuk memotivasi belajar ilmu duniawi. Meskipun demikian, bukan berarti kita mengingkari manfaat belajar ilmu duniawi. Karena hukum mempelajari ilmu duniawi itu tergantung pada tujuannya, apabila digunakan dalam kebaikan, maka baik dan apabila digunakan dalam keburukan, maka buruk (al-Usaimin, 2003).

\section{Keutamaan Ilmu}

Ada hal yang sangat disayangkan, bahwa ternyata beberapa majelis ilmu sudah tidak memiliki daya magnet yang dapat memikat umat Islam untuk duduk di dalamnya, bersimpuh di hadapan Allah SWT untuk meluangkan waktu dalam rangka mengkaji firman-firman Allah SWT dan hadist Nabi SAW., namun kebanyakan manusia lebih senang menyia-nyiakan waktu bersama dengan teman-teman mereka, menghabiskan waktu di instagram, twitter, atau media sosial lain dibandingkan duduk di majelis ilmu tesebut. Banyak faktor yang menyebabkan hal ini terjadi. Salah satunya adalah karena umat Islam belum mengetahui keutamaan dan keuntungan, mempelajari ilmu agama.

Banyak manusia belum mengetahui dan memahami untungnya duduk berjam-jam di majelis ilmu, dalam rangka untuk mengkaji ayat-ayat Allah SWT sebab fitrah manusia memang bertindak sesuai asas keuntungan. Faktanya adalah jika seseorang tidak mengetahui keuntungan atau manfaat suatu hal, maka ia tidak akan melakukan hal itu, maka begitu juga dengan ibadah. Oleh karena itu, semakin seseorang itu belajar dan mengetahui keuntungan-keuntungan salat, puasa, zakat, maka ia akan lebih semangat menjalaninya.

Terdapat banyak dalil dari kitab Allah SWT dan sunnah RasulNya terkait keutamaan ilmu dan pemilik ilmu, di antaranya adalah:

\section{1) Ilmu Memudahkan Jalan Menuju Surga \\ Hal ini sebagaimana ditunjukkan oleh hadits Abu Hurairah radhiyallahu 'anhu, Rasulullah}


ISSN 1979-9950 (print) || ISSN 2598-0033 (online), http://jurnal.umsu.ac.id/index.php/intiqad DOI: 10.30596/intiqad.v12i2.5197

Vol. 12, No. 2 (December 2020)

shallallahu 'alaihi wa sallam

bersabda:

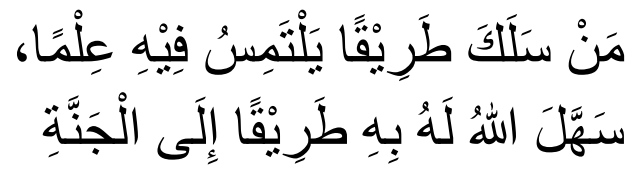

"Barang siapa menelusuri jalan untuk mencari ilmu padanya, Allah akan memudahkan baginya jalan menuju surga" (an-Naisaburi, tt.)

\section{2) Ilmu Adalah Warisan Para Nabi}

Hal ini sebagaimana dinyatakan oleh hadits:

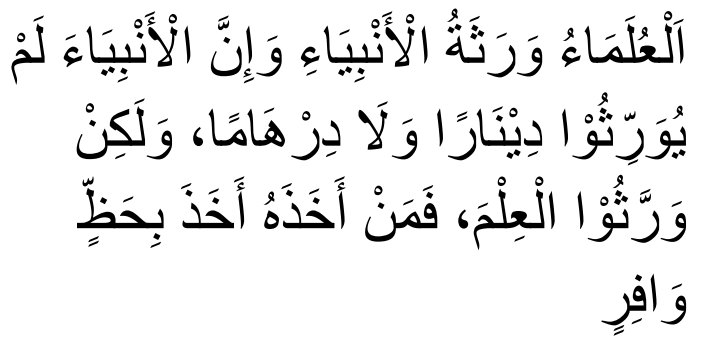

Para ulama adalah pewaris para nabi. Sesungguhnya para nabi tidak mewariskan dinar ataupun dirham, tetapi mewariskan ilmu. Maka dari itu, barang siapa mengambilnya, ia telah mengambil bagian yang cukup (as-Sijistani, $t$ t).

\section{3) Ilmu Akan Kekal Dan Akan Bermanfaat Bagi Pemiliknya Walaupun Dia Telah Meninggal}

Disebutkan dalam hadits,

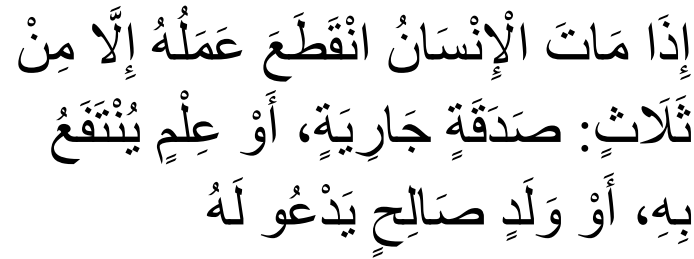

Jika seorang manusia meninggal, terputuslah amalnya, kecuali dari tiga hal: sedekah jariyah, ilmu yang bermanfaat, atau anak shalih yang berdoa untuknya" (an-Naisaburi, $t$ t).

\section{4) Allah Tidak Memerintahkan Nabi-} Nya Meminta Tambahan Apa Pun Selain Ilmu

Allah berfirman:

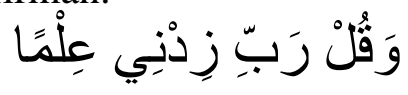

"Dan katakanlah, 'Wahai Rabb-ku, tambahkanlah kepadaku ilmu”' (Q.S. Thoha, 20:14).

Ini merupakan salah satu dalil tegas diwajibkannya menuntut ilmu.

\section{5) Orang Yang Dipahamkan Agama} Adalah Orang Yang Dikehendaki Kebaikan

\begin{tabular}{llr}
\multicolumn{1}{c}{ Dari } & Mu'awiyah, & Nabi \\
shallallahu & 'alaihi wa sallam \\
bersabda: & &
\end{tabular}

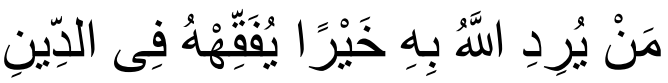

"Barangsiapa yang Allah kehendaki mendapatkan seluruh kebaikan, maka Allah akan memahamkan dia tentang agama” (al-Bukhari al-Ju'fi, 2002).

Yang dimaksud faqih dalam hadits bukanlah hanya mengetahui hukum syar'i, tetapi lebih dari itu. Dikatakan faqih jika seseorang memahami tauhid dan pokok Islam, 
ISSN 1979-9950 (print) || ISSN 2598-0033 (online), http://jurnal.umsu.ac.id/index.php/intiqad

DOI: 10.30596/intiqad.v12i2.5197

Vol. 12, No. 2 (December 2020)

serta yang berkaitan dengan syari'at Allah (al-Usaimin, 2003). Demikian dikatakan oleh Syaikh Muhammad bin Shalih Al-'Utsaimin dalam Kitabul 'Ilmi halaman 21.

6) Yang Paling Takut Pada Allah Adalah Orang Yang Berilmu

Hal ini bisa direnungkan dalam ayat berikut:

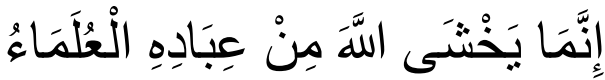

"Sesungguhnya yang takut kepada Allah di antara hambahamba-Nya, hanyalah ulama" (Q. Surat al-Fathir, 35: 28).

Ibnu Katsir rahimahullah berkata:

Sesungguhnya yang paling takut pada Allah dengan takut yang sebenarnya adalah para ulama (orang yang berilmu). Karena semakin seseorang mengenal Allah Yang Maha Agung, Maha Mampu, Maha Mengetahui dan Dia disifati dengan sifat dan nama yang sempurna dan baik, lalu ia mengenal Allah lebih sempurna, maka ia akan lebih memiliki sifat takut dan akan terus bertambah sifat takutnya (Ibn Katsir, 1998).
Para ulama berkata:

من كان بالله اعرف كان لله اخوف

"Siapa yang paling mengenal Allah, dialah yang paling takut pada Allah" (al-Usaimin, 2003).

\section{7) Orang Yang Berilmu Akan Allah Angkat Derajatnya}

Allah Ta'ala berfirman:

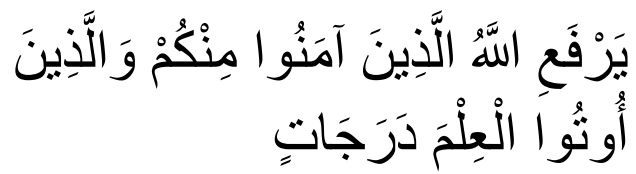

Niscaya Allah akan meninggikan orang-orang yang beriman di antaramu dan orang-orang yang diberi ilmu pengetahuan beberapa derajat (Q.S. al-Mujadalah, 58:11).

Allah Subhanahu wa Ta 'ala berfirman:

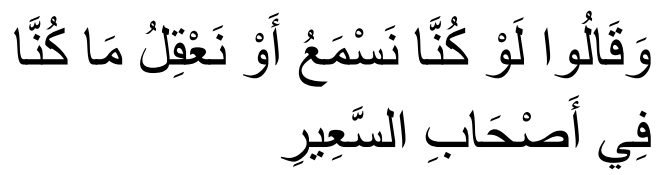

Dan mereka berkata: "Sekiranya kami mendengarkan atau memikirkan (peringatan itu) niscaya tidaklah kami termasuk penghunipenghuni neraka yang menyalanyala" (Q.S. al-Mulk, 67:10).

Allah SWT telah memberikan banyak kenikmatan, jika tidak digunakan untuk mempelajari firmanfirmanNya maka kita akan menjadi salah satu orang yang menyatakan 
ISSN 1979-9950 (print) || ISSN 2598-0033 (online), http://jurnal.umsu.ac.id/index.php/intiqad

DOI: 10.30596/intiqad.v12i2.5197

Vol. 12, No. 2 (December 2020)

yang Allah abadikan dalam surat Al-

Mulk ayat 10 di atas.

\section{Kedudukan Guru Dalam Islam}

Defenisi guru di dalam Kamus Besar Bahasa Indonesia adalah orang yang pekerjaannya (mata pencahariannya, profesinya) mengajar (Tim Penyusun Depdiknas, 2008). Menurut Ngalim Purwanto guru adalah orang yang pernah memberikan suatu ilmu atau kepandaian kepada seseorang atau sekumpulan orang (1994), sedangkan menurut Ahmad Tafsir bahwa guru adalah orang-orang yang bertanggung jawab terhadap perkembangan anak didik dengan mengupayakan perkembangan seluruh potensi anak didik, baik potensi kognitif, afektif, maupun psikomotorik.

Sedangkan menurut Hadari Nawawi bahwa pengertian guru dapat dilihat dari dua sisi. Pertama secara sempit, guru adalah orang yang berkewajiban mewujudkan program kelas, yakni orang yang kerjanya mengajar dan memberikan pelajaran di kelas. Sedangkan secara luas diartikan bahwa guru adalah orang yang bekerja dalam bidang pendidikan dan pengajaran yang ikut bertanggung jawab dalam membantu anak-anak dalam mencapai kedewasaan masing-masing (Hadari Nawawi, 1982).

Sedangkan menurut Ibn Manzur di dalam kitabnya Lisanul 'Arab ia menjelaskan bahwa guru adalah:

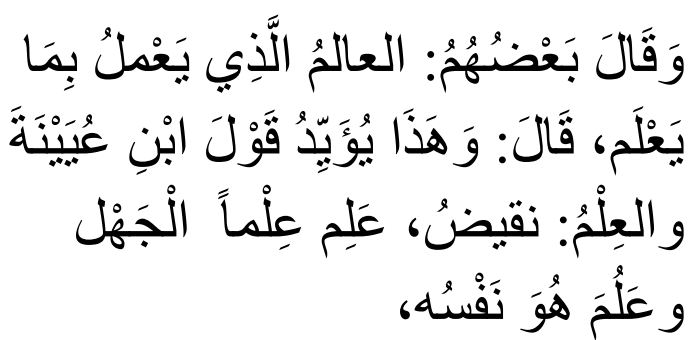

Sebagian orang mengatakan bahwa al-'Alim/al-Mu'allim adalah orang yang mengamalkan apa yang ia ketahui atau mengajarkan apa yang telah ia ketahui, kemudian Ibn Manzur mengatakan lagi bahwa pendapat sebagian orang tadi mendukung perkataan Ibn 'Uyainah yang mengatakan bahwa ilmu adalah lawan kejahilan, dan kata 'alima, 'ilman, dan 'aluma adalah satu padanan kata (ibn Manzur, tt).

Dari penjelasan di atas maka jelaslah bagi kita bahwa di dalam Islam kata guru atau المعلم berasal dari kata 'allama, yu'allimu, ta'liman, mu'allimun atau almu'allim/ , علم , يعلم , تعليما Serang yang berarti orang yang mengajarkan ilmu, sehingga setiap orang yang berilmu harus mengamalkan ilmunya, dan setiap muslim dan muslimah harus memiliki ilmu dalam 
INTIQAD: JURNAL AGAMA DAN PENDIDIKAN ISLAM

ISSN 1979-9950 (print) || ISSN 2598-0033 (online), http://jurnal.umsu.ac.id/index.php/intiqad

DOI: 10.30596/intiqad.v12i2.5197

Vol. 12, No. 2 (December 2020)

menjalankan agamanya, karena kita adalah ummat yang mengumpulkan antara ilmu dan amal.

Sesungguhnya kedudukan guru dan urgensinya di dalam masyarakat memiliki tempat yang sangat tinggi dan luar biasa, karena dari tangan seorang gurulah lahir generasi yang membangun peradaban, yang menjadi pemimpin dan pembimbing bagi ummat sepanjang zaman, dan profesi guru adalah sebaikbaik dan semulia-mulia profesi dalam setiap masyarakat, dan sungguh mulia seorang guru yang melaksanakan profesi ini dengan baik.

Ibn Abdil Bar memberikan penjelasan tetang keutamaan guru di dalam kitabnya, sebagaimana dalam riwayat berikut.

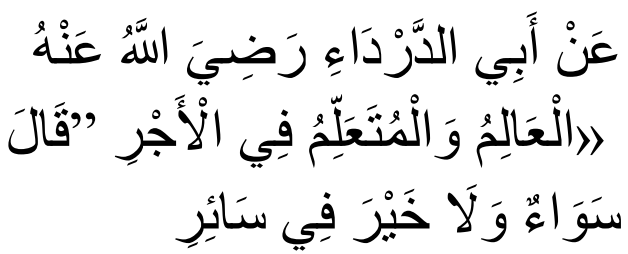

Dari Abu Darda' ra. ia berkata, orang 'alim/pengajar/guru dan orang yang belajar sama dalam hal pahala, dan tidak ada kebaikan diseluruh manusia setelah pengajar/guru dan penuntut ilmu (Ibn Abdil Bar, 1992).
Dari tangan seorang gurulah akan lahir genersai-generasi yang akan membangun peradaban, panglima tentara dan untuk mendapatkan kedudukan yang tinggi, dan untuk mewariskan perdaban yang tinggi agar dapat diambil faedahnya oleh orang-orang yang hidup disepanjang zaman.

\section{Figur-figur Guru di Zaman Nabi Muhammad SAW}

Sesungguhnya semua para sahabat ra. adalah guru, karena agama yang mulia ini sampai kepada kita berkat kegigihan dan kesugguhan mereka dalam menyampaikan dan mengajarkan Islam kepada orang-orang yang datang setelah mereka dari kalangan tabi'in, dan begitu juga dengan orang-orang tabi'in menyampaikan kepada orang-orang yang datang setelah mereka, dan begitulah seterusnya sehingga sampai kepada kita hari ini, walaupun harus diakui bahwa aktivitas keguruan masing-masing mereka berbeda-beda sesuai dengan keadaan mereka. Penulis kali akan menurunkan beberapa sahabat sebagai sampel dan wakil dari sekalian sahabat ra, mereka itu di antaranya adalah sebagai berikut. 


\section{a. Mush'ab ibn Umair ra}

Beliau adalah Mush'ab al-Khair ibn Umair ibn Hasyim ibn Abdil manaf ibn 'Abd ad-Dar (Abu Zubair, 1951), atau Mush'ab ibn Umair ibn Hasyim ibn 'Abd al-Manaf ibn 'Abd ad-Dar ibn Qushaiy ibn Kilab ibn Murrah alQurasyi al'Abdariy. Sedangkan kuniyahnya/gelarannya adalah Abu Abdillah (ibn al-Asir, tt.).

Ibn Sa'ad mengatakan, telah menceritakan kepada kami Muhammad ibn Umar ia berkata, telah memberitakan kepada kami Ibrahim ibn Muhammad al'Abdari dari ayahnya dia berkata: Mus'ab ibn Umair ra. adalah salah seorang pemuda yang ganteng dan gagah yang ada di kota Makkah, dan adalah orang tuanya sangat menyayanginya, dan ibunya adalah orang yang memiliki banyak harta, dan ibunya memakaikannya pakaian yang paling indah dan yang paling bagus, dan ia adalah pemuda yang sangat wangi dan harum, dan Rasululullah SAW manakala mengingatnya ia berkata: Tidaklah aku melihat salah seorang di Makkah yang lebih bagus rambutnya, tidak ada pula yang lebih lembut pakaiannya, dan tidak ada juga yang lebih mewah kehidupannya dari Mus'ab ibn Umair ra.
Manakala ia mendengar Rasulullah SAW mengajari, menyeru serta mengajak manusia untuk masuk ke dalam Islam di kediaman Arqam ibn Abi al-Arqam ra., maka ia masuk ke dalamnya, maka ia masuk Islam dan ia membenarkannya, lalu ia keluar kemudian ia menyembunyikan keislamannya karena ia takut terhadap ibunya dan kaumnya, maka ia sering datang kepada Rasulullah SAW dalam keadaan sembunyi-sembunyi,

Maka ketika itu Usman ibn Talhah melihatnya sedang shalat, lalu Usman pun memberitahu ibunya dan kaumnya, maka mereka mengurungnya, maka ia pun terus ditahan dan dikurung sehingga ia berhijrah yang pertama ke negeri Habsyah. Manakala ia kembali bersama kaum muslimin dari negeri Habsyah maka ia sudah berubah dan kuat dan agak kasar, sehingga ibunyapun tidak lagi mencela dan mencacinya.

Kemudian setelah Mus'ab ibn Umair kembali dari negeri Habsyah beliau kembali hijrah ke Madinah setelah Aqobah yang pertama untuk mengjari manusia Alquran dan untuk menjadi imam mereka dalam shalat mereka (Ibn Asir, tt.). 
INTIQAD: JURNAL AGAMA DAN PENDIDIKAN ISLAM

ISSN 1979-9950 (print) || ISSN 2598-0033 (online), http://jurnal.umsu.ac.id/index.php/intiqad

DOI: 10.30596/intiqad.v12i2.5197

Vol. 12, No. 2 (December 2020)

Manakala orang-orang yang ikut dalam Aqabah yang pertama sebanyak 12 orang itu telah pergi, dan agama Islam telah menyebar di negeri Anshar, maka orang-orang Anshar mengutus seorang laki-laki kepada Rasulululah SAW untuk membawa surat yang isinya agar beliau SAW mengirim dan mengutus seorang lakilaki dari salah seorang sahabatnya untuk mengajari mereka tentang dinul Islam yang mulia ini,

Kemudian untuk mengajari mereka tentang membaca Alquran, maka kemudian Rasulullah SAW mengutus kepada mereka Mus'ab ibn Umair ra., lalu Mus'ab ibn Umar ra. pun datang ke kota Madinah alMunawwarah, dan beliau tinggal di rumah Sa'ad ibn Zararah, dan Mus'ab mendatangi orang-orang Anshar di rumah mereka dan ia datang juga ke kepala suku-suku mereka, lalu ia menyeru mereka untuk masuk ke dalam Islam, dan membacakan dan mengajarkan kepada mereka Alquran, maka masuk Islam lah orang-orang Anshar, mulai dari 1 orang laki-laki, 2 orang laki-laki dan begitu seterusnya, sehingga agama Islam telah tampak dengan terang dan berkembang di kampung-kampung

orang-orang

Anshar seluruhnya.

Kemudian Mus'ab ibn Umair ra. tetap gigih dan serius dalam mengajari dan membimbing orangorang Anshar bagaimana cara membaca Alquran dengan baik dan benar, maka beliau ra. menuliskan sepucuk surat kepada Rasulullah SAW untuk meminta izin agar ia bersama orang-orang Anshar dapat melaksanakan shalat jum'ah secara berjama'ah, maka beliau SAW mengizinkannya untuk pelaksanaan shalat juma'at tersebut dengan mengirimkan sepucuk surat juga ke beliau SAW. Surat yang dikirmkan oleh Rasulullah SAW kepada Mus'ab ibn Umair ra, itu berbunyi:

Perhatikanlah olehmu wahai Mus'ab mulai hari ini, orangorang yahudi menampakkan ibadah mereka pada hari sabtu, maka jika matahari sudah tergelincir pada hari jum'at, maka hendaklah engkau mendekatkan dirimu kepada Allah SWT dengan melakukan shalat dua raka'at, kemudian berkhutbahlah untuk manusia.

Kemudian Mus'ab ibn Umair ra bersama orang-orang Anshar melakukan shalat jum'at secara berjama'ah di rumah 
Sa'ad ibn Khaisamah ra., dan jumlah mereka pada waktu itu 12 orang lakilaki, dan tidaklah Sa'ad ibn Khaisamah ra. menyembelih bagi mereka kecuali hanya seekor kambing saja, maka dari peristiwa ini tercatatlah bahwa orang yang pertama sekali melakukan shalat jum'at secara berjama'ah di dalam agama Islam adalah Mus'ab ibn Umair ra., namun ada sebagian kaum khususnya dari orang-orang Anshar yang meriwayatkan bahwa sesungguhnya orang yang pertama sekali melakukan shalat jum'at secara berjama'ah adalah Abu Umamah As'ad ibn Zararah ra., kemudian Mus'ab ibn Umair ra. keluar dari Madinah bersama 70 orang yang telah berjanji setia dengan Rasulullah SAW (Ibn Saad, ...).

Sahabat Mus'ab ibn Umair ra. ikut berperang bersama Rasulullah SAW. pada peperangan Uhud, dan beliau memegang bendera kaum muslimin sehingga ia terbunuh ditangan Ibn Qomi'ah al-Laisi, kerena Ibn Qomi'ah al-Laisi mengira bahwa Mus'ab ibn Umair ra. adalah Nabi Muhammad SAW., maka setelah ia membunuh Mus'ab ibn Umair ra ia pun pergi ke barisan kafir Quraisy seraya berkata: aku telah membunuh Muhammad SAW. Dan setelah gugur Mus'ab ibn Umair ra maka bendera kaum muslimin diserahkan oleh Rasulullah kepada Ali ibn Abi Thalib ra (Ibn Yasar al-Matlabi, 1978).

Begitulah kirannya kegigihan dan perjuangan dari seorang guru yang mulia, Mus'ab ibn Umair ra dalam mengajari dan mendidik manusia sehingga mereka mampu beribadah kepada Allah SWT dengan ikhlas, berakhlak mulia dengan mengikuti ajaran, petunjuk, arahan dan bimbingan dari guru pertama khususnya kepada kaum muslimin dan kepada manusia secara umum yaitu Muhammad SAW. Maka Mus'ab ibn Umair adalah seorang guru, seorang mujahid dan seorang yang syahid di jalan Allah SWT.

\section{b. Mu'az ibn Jabal ra.}

Beliau adalah Mu'az ibn Jabal ibn 'Amrin ibn Aus ibn 'Aiz ibn 'Adai ibn Ka'ab ibn 'Amrin ibn Sa'ad akhi Salamah ibn Sa'ad ibn Ali ibn Asad ibn Syaradah ibn Yazid ibn Jasyam ibn alKhazraj, dan Mu'az ibn Jabal digelari dengan Abu Abdirrahman (ibn Saad).

Mu'az ibn Jabal ra. adalah termasuk dari golongan sahabat AsSabiqunal Awwalun yaitu orang-orang yang pertama masuk Islam, karena ia 
memeluk Islam pada Bai'atul Aqabah yang ke dua, pada usia beliau 18 tahun bersama 70 orang dari kaum Anshar yang hadir pada ba'iat tersebut. Dan ia ikut dalam perang Badar dan peperangan yang lainnya bersama Rasululullah SAW., dan beliau dipersaudarakan oleh Rasulullah SAW dengan Abdullah ibn Mas'ud ra (ibn Asir, tt.).

Kemudian Rasulullah SAW menugaskan 'Attab ibn Usaid untuk mengurusi kota Makkah, kemudian beliau menggantikan 'Attab ibn Usaid dengan Mu'az ibn Jabal dan Abu Musa al-Asy'ari ra., yang keduanya mengajari manusia/orang-orang Makkah mengaji Alquran, dan juga mengajari mereka tentang fiqh dalam agama ini (al-Waqidi, 1989).

Sahabat Mu'az ibn Jabal ra adalah sahabat yang mulia, dan ia memiliki kedekatan yang luar biasa dengan Rasulullah SAW., dan ia mendapatkan beberapa pujian dari beliau SAW., yang mengindikasikan bahwa beliau ra memiliki keutamaan dan kedudukan yang tinggi di sisi Rasulullah SAW., di antara pujian itu adalah:

1) Mu'az ibn Jabal adalah orang yang paling paham dan mengerti tentang perkara yang halal dan perkara yang haram.

Ibn Sa'ad mengatakan, telah mengkisahkan kepada kami Affan ibn Muslim, telah menceritkan kepada kami Wuhaib, telah mengkisahkan kepada kami Khalid, dari Kilabah, dari Anas ibn al-Malik ra., dari Nabi SAW ia berkata: Orang yang paling 'alim atau orang yang paling mengerti tentang perkara yang halal dan perkara yang haram dari umatku ini adalah Mu'az ibn Jabal (ibn Saad, tt.).

2) Mu'az ibn Jabal ra berdiri di depan para ulama pada hari kiamat

Ibn Sa'ad mengatakan telah mengkisahkan kepada kami Muhammad ibn Umar dari Sulaiman ibn Bilal dan Na'man ibn Umarah ibn Ghazaiyyah dari Muhammad ibn Ka'ab al-Qurazhi, ia bercerita: Telah berkata Rasulullah SAW: Mu'az ibn Jabal ra datang pada hari kiamat selangkah di depan para ulama.

3) Mu'az ibn Jabal ra adalah utusan Rasululllah SAW yang direstui oleh Nabi Muhammad SAW.

Ibn Sa'ad mengatakan telah mengkisahkan kepada kami Yazid ibn Harun, ia berkata, telah 
ISSN 1979-9950 (print) || ISSN 2598-0033 (online), http://jurnal.umsu.ac.id/index.php/intiqad DOI: 10.30596/intiqad.v12i2.5197

Vol. 12, No. 2 (December 2020)

mengkisahkan kepada kami Syu'bah ibn Hajjaj dari Muhammad ibn 'Aun Muhammad ibn 'Ubaidillah dari Haris ibn Amr as-Saqafi ibn Akhi al-Mughirah, telah mengkisahkan kepada kami sahabat-sahabat kami, dari Mu'az ibn Jabal ra ia berkata, manakala Rasulullah SAW. mengutus Mu'az ibn Jabal ke Yaman, beliau SAW berkata kepadanya:

Dengan apakah engkau memutuskan perkara jika dihadapkan kepadamu, Mu'az berkata aku akan memutuskannya dengan hukum Allah SWT., kemudian beliau SAW berkata lagi, jika hukum perkara itu tidak ada di pada Kitabullah, Mu'az menjawab: Aku akan memutuskan perkara tersebut dengan keputusan yang telah diputuskan oleh Rasulullah SAW kemudian beliau SAW berkata lagi, jika hukum perkara itu tidak ada di pada keputusan Rasululullah SAW., Mu'az menjawab: Aku akan memutuskan perkara tersebut dengan ijtihadku, kemudian Mu'az berkata: lalu Rasululullah SAW. menepuk dadaku seraya ia berkata: Segala puji hanya milik Allah SWT. yang telah mencocokkan/mensesuaikan utusan Rasulullah SAW terhadap apa yang telah diridhai oleh Rasulullah SAW.(ibn Saad, tt.).
4) Mu'az ibn Jabal ra. orang yang paling mengerti tentang fiqh

Ibn Sa'ad mengatakan, telah mengkisahkan kepada kami Muhammad ibn Umar, telah mengkisahkan kepada kami Musa ibn Ali ibn Rabah dari ayahandanya, ia berkata: Umar ibn al-Khattab ra berkhutbah di depan orang banyak, beliau berkata: Barang siapa yang hendak bertanya tentang fiqh maka hendaklah ia mendatangi Mu'az ibn Jabal ra.

5) Mu'az ibn Jabal ra menjadi guru ke Yaman

Muhammad ibn Yusuf as-Shalihi as-Syami mengutip riwayat dari ibn Abbas ra., bahwa Rasulullah SAW mengutus Mu'az ke Yaman, lalu beliau berkata kepadanya:

Sesungguhnya engkau akan mendatangi ahlul kitab yaitu orang-orang Yahudi dan Nasrani, maka hendaklah yang pertama engkau serulajak mereka adalah beribadah kepada Allah SWT., maka apa bila mereka telah mengetahui Allah SWT., maka beritakanlah kepada mereka bahwasanya Allah SWT telah mewajibkan kepada mereka shalat 5 (lima) waktu dalam sehari dan semalam, maka apabila mereka 
INTIQAD: JURNAL AGAMA DAN PENDIDIKAN ISLAM

ISSN 1979-9950 (print) || ISSN 2598-0033 (online), http://jurnal.umsu.ac.id/index.php/intiqad

DOI: 10.30596/intiqad.v12i2.5197

Vol. 12, No. 2 (December 2020)

telah melakukan hal tersebut, maka beritakanlah kepada mereka bahwa Allah SWT telah membebankan kepada mereka zakat yang di ambil dari harta orang-orang kaya mereka, dan diberikan untuk orang-orang fakir mereka, maka apa bila mereka mamatuhimu maka ambil harta zakat tersebut dari mereka, dan engkau menjaga harta-harta mereka yang paling mulia/janganlah engkau mengambil harta yang paling mereka cintai untuk zakat, dan berhati-hatilah engkau terhadap dakwah atau do'a orang-orang yang di zalimi, maka sesungguhnya do'a orang-orang yang dizalimi tidak ada penghambat antara ia dengan Allah SWT. (AS-Syami, 1993).

Dari pemaparan di atas tampak jelaslah bagi kita bahwa Mu'az ibn Jabal ra adalah orang yang 'alim yang diakui oleh Rasulullah SAW., sehingga beliau diberikan kepercayaan untuk mengemban tugas yang berat namun sangat mulia yaitu menjadi guru kepada orang-orang yaman, dan bahkan al-Imam at-Tabari mengatakan bahwa Mu'az ibn Jabal ra diutus oleh Nabi Muhammad SAW untuk menjadi guru dan pengajar di 2 (dua) negeri yaitu negeri Yaman dan Hadra Maut (at-Tabari, 1966).

Ibn Sa'ad mengatakan telah memberitakan kepada kami Muhammad ibn Umar ia berkata: Telah memberitakan kepada kami Ayyub ibn Nu'man dari ayahnya dari kaumnya ia berkata: Telah memberitakan kepada kami Ishaq ibn Kharijah ibn Abdillah ibn Ka'ab ibn al-Malik, dari ayahandanya dari kakeknya mereka berkata: Mu'az ibn Jabal adalah laki-laki yang tinggi, ganteng dan tampan lagi putih kulitnya, bagus rambutnya, kedua alisnya bertemu, rambutnya ikal, dan ia meninggal karena terkena penyakit Tha'un pada saat ia berada di Syam di sebelah Urdun pada usia beliau yang ke 38 tahun (ibn Saad, tt.).

\section{At-Tufail ibn Amr}

Beliau adalah At-Tufail ibn Amr ibn Tarif ibn al-Ash ibn Sa'labah ibn Salim ibn Fahm ibn Ghanam ibn Daus ad-Dausi ra., dari negeri Daus, dan ia memeluk agama Islam dan membenarkan Nabi Muhammad SAW di Makkah (Ibn Saad, tt.).

Ibn Hisyam menceritakan kisah masuk Islamnya At-Tufail ibn 'Amr adDausi, bahwa orang-orang Quraisy melarangnya agar tidak mendengar sesuatu dari Nabi Muhammad SAW. Ibn Ishaq mengatakan bahwa Rasulullah SAW memperhatikan dan melihat apa 
yang dilakukan kaumnya terhadap dirinya, maka beliau SAW bersungguhsungguh dalam menyampaikan nasehat kepada mereka, dan ia mengajak mereka untuk menuju kesalamatan, maka mulailah orang-orang Quraisy melarang dan memperingatkan manusia dan orang-orang arab yang datang kepada mereka dari mendengar sesuatu dari Nabi Muhammad SAW.

At-Tufail ibn 'Amr ad-Dausi menceritkan bahwa ia datang ke Makkah dan Rasulullah SAW ada di sana, maka At-Tufail pun berjalan menuju beliau SAW., dan beberapa orang Quraisy pun membuntuti dan mengikuti At-Tufail, dan At-Tufail adalah laki-laki yang mulia, dan ia adalah seorang penyair yang pandai, maka orang-orang Quraisy bertanya kepadanya, wahai At-Tufail sesungguhnya kamu datang ke negeri kami, dan Muhammad SAW yang berada di antara kami telah membuat masalah dan mempersulit kami, dan ia telah merusak jama'ah kami dan mencerai beraikan urusan kami. Dan sungguh perkataannya seperti perkataan tukang sihir yang dapat memisahkan seorang laki-laki dengan ayahandanya, antara seorang laki-laki dengan saudaranya, antara seorang laki-laki dengan istrinya, dan kami takut dan khawatir terhadap dirimu dan kaummu akan menimpa kamu dan kaummu sebagaimana yang telah terjadi pada kami, maka jangan engkau ajak bicara dia, dan jangan engkau dengar sesuatu dari dia (Abu Muhammad Jamaluddin, 1955).

Kemudian At-Tufail mengatakan demi Allah SWT mereka selalu bersamaku sehingga aku memutuskan, bahwa aku tidak akan mendengarkan sesuatu dari beliau SAW dan aku tidak akan mengajaknya untuk berbicara, sehingga aku melatakkan kapas di dalam kedua telingaku ketika aku hendak pergi ke Masjid agar tidak masuk sesuatu dari perkataannya ketelingaku, dan aku tidak mau mendengar sesuatu darinya, maka ketika itu ia berangkat ke Masjid, ternyata Rasulullah SAW sedang shalat di dekat Ka'bah, maka At-Tufail berdiri di dekat Nabi Muhammad SAW., maka Allah SWT enggan kecuali memperdengarkan sebagian perkataannya kepadaku, maka At-Tufail mendengar perkataan yang indah dari beliau, lalu ia berkata di dalam dirinya celakalah ibuku, demi Allah SWT sesunguhnya aku adalah seorang lakilaki yang pintar, seorang penyair tidak 
ada yang tersembunyi atas diriku dari hal-hal yang baik dan hal-hal yang jelek, maka tidak ada yang mengahalangiku dari mendengar sesuatu dari laki-laki ini (Nabi Muhammad SAW), maka jika yang ia bawa adalah kebaikan maka akan aku terima, dan jika yang ia bawa adalah kejelekan maka akan aku kutinggalkan.

Kemudian aku terdiam sehingga Rasulullah SAW pergi ke rumahnya, maka aku mengikutinya sehingga beliau masuk ke dalam rumahnya, maka akupun ke dalamnya, maka aku katakan kepadanya wahai Muhammad sesungguhnya kaummu telah menceritakan kepadaku tentang dirimu begini dan begitu, maka tawarkanlah kepadaku tentang urusanmu, maka Rasulullah SAW menawarkan Islam kepadaku seraya ia membacakan beberapa ayat dari Aquran, maka demi Allah SWT tidaklah aku pernah mendengar perkataan yang lebih bagus dan lebih indah darinya, dan tidak pula ada urusan yang lebih adil dari urusannya maka akupun masuk Islam dan aku bersyahadat syahadatal haq, yaitu mengucapkan La Ilaha Illallahu, Muhammad Darrasulullah.
Manakala At-Tufail ibn 'Amr ra telah memeluk Islam, maka beliapun berkata kepada Nabi Muhammad SAW., wahai Nabiyullah sesungguhnya saya adalah orang yang dipatuhi dan dituruti di tengah-tengah kaumku, dan saya akan kembali kepada mereka, dan aku akan mengajak dan menyeru mereka untuk masuk ke dalam Islam, maka berdo'alah kepada Allah SWT untukku agar Ia menjadikan untukku sebuah ayat/tanda untukku sebagai penolong kepada mereka terhadap apa yang aku seru atau ajak mereka kepadanya, maka beliau SAW berdo'a kepadanya: Ya Allah jadikanlah kepadanya ayat/tanda, maka At-Tufail pun berkata: Aku keluar kepada kaumku, sehingga aku sampai di Saniah (nama tempat) terlihat ada cahaya di wajahku seperti lampu, maka aku berkata: "Ya Allah jadikannlah cahaya itu tidak pada wajahku, karena aku takut orang-orang akan menduga bahwa hal itu merupakan hukuman yang diberikan kepadaku karena aku meniggalkan agama mereka", maka setelah itu cahaya itu pun berpindah ke ujung tongkatku, maka orang-orangpun memperhatikan cahaya yang ada diujung tongkatku seperti lentera yang digantung, maka akupun bergegas turun 
INTIQAD: JURNAL AGAMA DAN PENDIDIKAN ISLAM

ISSN 1979-9950 (print) || ISSN 2598-0033 (online), http://jurnal.umsu.ac.id/index.php/intiqad

DOI: 10.30596/intiqad.v12i2.5197

Vol. 12, No. 2 (December 2020)

dari saniah tersebut sehingga akupun bersama mereka.

Setelah At-Tufail ibn 'Amr ra sampai di kampungnya dan ia telah bersama keluarganya, maka datanglah ayahnya untuk menemuinya, dan ayahnya adalah seorang yang tua renta, maka At-Tufail ibn 'Amr ra. berkata kepada ayahnya, menjauhlah dariku wahai ayahku, engkau bukan bagian dariku dan aku bukan bagian darimu, maka ayahnya berkata kepadanya mengapa wahai anakku, maka At-Tufail ibn 'Amr ra mengatakan: Aku telah memeluk agama Islam dan aku telah mengikuti agama Nabi Muhammad SAW., maka ayahnya pun berkata kepadanya: wahai anakku agamaku adalah agamamu, maka At-Tufail ra berkata kepadanya, maka pergilah wahai ayahku, lalu mandilah, dan bersihkanlah pakaianmu, kemudian datanglah kepadaku, aku akan mengajarkan kepadamu apa yang telah aku pelajari, maka ayahnya pun pergi untuk mandi, lalu membersihkan pakaiannya, lalu ayahnya datang kepadanya, kemudian At-Tufail ra menawarkan Islam kepadanya maka masuk Islamlah ayahnya.
Kemudian istri At-Tufail ibn 'Amr ra datang kepadanya, maka At-Tufail ra berkata kepadanya, maka At-Tufail ibn 'Amr ra berkata menjauhlah dariku, aku bukan bagian darimu dan engkau bukan bagian dariku, maka istrinya bertanya kepadanya mengapa wahai suamiku, maka beliaupun menjawab agama Islam telah memisahkan aku dan engkau, dan aku mengikuti Nabi Muhammad ra., maka istrinya pun menjawab sesungguhnya agamaku adalah agamamu, lalu At-Tufail ra berkata kepadanya pergilah engkau ke Hina Dzi Syar (nama tempat yang ada sungai padanya), maka istrinyapun mandi lalu datang kepada At-Tufail ibn 'Amr ra kemudian At-Tufail ibn 'Amr menawarkan Islam kepadanya maka Istrinyapun masuk Islam.

Selanjutnya At-Tufail ibn 'Amr ra mengajari kaumnya (orang-orang Daus) agar mereka masuk dan memeluk agama Islam, maka mereka agak lambat dan kurang merespon pengajarannya dan dakwahnya, lalu ia pergi kembali ke Makkah untuk bertemu dengan Rasulullah SAW dan ia mengatakan kepada beliau, wahai Nabiyyullah sesungguhnya perkara-perkara yang melalaikan manusia telah mengalahkan 
aku untuk menyeru orang-orang daus, maka berdo'alah engkau untuk mereka, maka beliau SAW. berdo'a: Ya Allah berikanlah petunjuk kepada orang-orang Daus, lalu beliau SAW mengatakan kepada At-Tufail ra pulanglah engkau ke negerimu dan serulah kaummu dan berlemah lembutlah dengan mereka, maka At-Tufail ra mengatakan senantiasalah aku berada di negeri Daus, aku menyeru mereka agar mereka masuk dan memeluk agama Islam sehingga Rasulullah SAW. berhijarah ke Madinah, dan setelah beliau SAW selasai dari perang Badar, Uhud dan Khandak. Kemudian aku menemui Rasulullah SAW. bersama kaumku yang telah masuk Islam, dan Rasulullah SAW sedang berada di Khaibar, sehingga aku dan kaumku sampai di Madinah dengan 70 atau 80 kepala keluarga dari suku Daus, kemudian kami menemui Rasulullah SAW., lalu beliau SAW. mempersatukan kami bersama dengan kaum muslimin. Dan salah seorang sahabat yang mulia yang banyak meriwayat hadis dari Nabi Muhammad SAW., yaitu Abdurahman ibn Shakhr ad-Dausi (Abu Hurairah ra) memeluk Islam melalui ajakan dan seruan AtTufail ibn 'Amr ra di Yaman, dan beliaupun ikut bersama rombongan AtTufail ra ke Madinah untuk bertemu dengan Rasululla ra (Ibn Saad, tt).

Akhir At-Tufail ibn 'Amr ra ketika ia kembali bersama kaumnya ke Madinah untuk bertemu dengan Nabi Muhammad SAW., dan ia tetap bersama beliau SAW sehingga beliau SAW diwafatkan oleh Allah SWT. Dan tatkala beliau SAW wafat maka banyak dari kalangan orang-orang Arab yang murtad serta keluar dari Islam, oleh karena itu At-Tufail ibn 'Amr bersama kaum muslimin keluar ke medan juang sebagai seorang Mujahid fi sabilillah ke Yamamah, lalu beliaupun gugur sebagai seorang yang syahid di Yamamah tesebut (al-Asqalani, 1994).

\section{Kesimpulan}

Islam adalah agama yang mengumpulkan antara ilmu dan amal, maka sejatinya setiap pemeluknya harus memiliki ilmu dan mengamalkan ilmu tersebut dengan baik. Keutamaan ilmu dan ahli ilmu sangat jelas di dalam agama Islam yang mulia ini, bahwa ilmu menjadi penyebab mudahnya jalan sesorang untuk menuju surga, dan ia merupakan para nabi yang akan kekal dan akan bermanfaat bagi yang 
INTIQAD: JURNAL AGAMA DAN PENDIDIKAN ISLAM

ISSN 1979-9950 (print) || ISSN 2598-0033 (online), http://jurnal.umsu.ac.id/index.php/intiqad

DOI: 10.30596/intiqad.v12i2.5197

Vol. 12, No. 2 (December 2020)

memiliknya, maka seyogyanya seseorang itu senantiasa meminta tambahan ilmu kepada maha pemilik ilmu Allah SWT. Untuk menilai apakah seseorang itu dikehendaki oleh Allah SWT kebaikan kepadanya atau tidak dapat dilihat dari pemahamannya terhadap agama ini, jika pemahamannya baik, maka ia termasuk orang yang diberikan oleh Allah SWT kepadanya kebaikan, sebab ia akan menjadi orang yang paling takut kepada Allah SWT.

Para sahabat ra. adalah merupakan murid-murid hasil didikan Nabi Muhammad SAW, mereka telah memberikan contoh dan keteladanan yang indah dalam hal keberanian, sikap adil, tawadhu' dan lain-lain, walaupun hal tersebut harus dengan membayar harga diri yang mahal, maka hal ini sesungguhnya akan menambah $i z z a h / k e m u l i a a n$ dan wibawa seseorang, dan tidak akan mengurangi kehormatannya sedikitpun, dan barang siapa yang menyangka selain hal itu, maka ia telah keluar dari jalan yang benar. Di antara figur yang ada dizaman Nabi Muhammad SAW., adalah Mus'ab Ibn Umair ra., Muaz Ibn Jabal ra, AtTufail ibn Amr ra.

\section{Daftar Pustaka}

Abu Zubair, Mus'ab ibn Abdillah ibn Mus'ab ibn Sabit ibn Abdillah ibn Zubair Abu Abdillah (1951). Nasab Quraisy, al-Qahirah: Dar alMa'arif.

Al-Asqalani, Abu Fadl Ahmad ibn Ali ibn Muhammad ibn Ahmad ibn Hajar. (1994). Al-Ishabah fi Tamyizi as- Sahabah. Beirut: Dar al-Kutub al-'Ilmiyyah.

Ad-Dimasyqi, Ismail ibn Umar ibn Kasir alqurasyi al-Bashari. (1998). Tafsir Alquran al-'Azim. Beirut: Daarul Kutub Al-Ilmi'ah.

Hadari, Nawawi. (1982). Organisasi Sekolah dan Pengelolaan Kelas. Jakarta: Gunung Agung.

al-Hamd, Muhammad ibn Ibrahim, Ma'al Mu'allimin. (2002). ter. Ahmad Syaikhu, Bersama Para Pendidik Muslim. Jakarta: Daarul Haq.

Jamaluddin, 'Abd al-Malik ibn Hisyam ibn Abu Ayyub al-Humairi alMu'afiri Abu Muhammad. (1955). As-Sirah an-Nabawiyyah li ibn Hisyam, Mesir: Mustafa al-Babi al-Halabi. 
INTIQAD: JURNAL AGAMA DAN PENDIDIKAN ISLAM

ISSN 1979-9950 (print) || ISSN 2598-0033 (online), http://jurnal.umsu.ac.id/index.php/intiqad

DOI: 10.30596/intiqad.v12i2.5197

Vol. 12, No. 2 (December 2020)

Al-Ju'fi, Muhammad ibn Isma'il Abu Abdillah al-Bukari. (2002). AlJami' al-Musnad as-Shahih alMukhtasar min Umuri Rasulullah Shallallahu 'Alaihi Wasallam wa Sunanih wa Ayyamihi. Riyad: Daar Tuqun Najah.

Majah, Ibnu. Sunan Ibn Majah (tt.). Tahqiq Muhammad Fuad 'Abd. alBaqi’. Kairo: Dar Ihya' al-Kutub al-'Arabiah.

Al-Matlabi, Muhammad ibn Ishaq ibn Yasar. (1978). Sirah ibn Ishaq. Beirut: Dar al- Fikri.

An-Naisaburi, Muslim ibn Hajjaj Abu Hasan al-Qusyairi. (tt). Al-Musnad as-Shahih al-Mukhtasar binaqli al'adli ila Rasulullahi Shalllahu 'alaihi wasallam. Beirut: Dar Ihya at- Turas al-'Arabi.

Purwanto, Ngalim. (1994). Ilmu Pendidikan Teoritis dan Praktis. Bandung: Remaja Rosdakarya.

Al- Qurtuubi, Abu Umar Yusuf ibn Abdillah ibn Muhammad ibn 'Abd al-Bar ibn 'Asim an-Namari. (1992). Al-Isti'abi fi Ma'rifatilAshab. Beirut: Dar al-Jil.
As-Sijistani, Abu Dawud Sulaiman ibn al-'Asy'aṡ ibn Ishak ibn Basyir ibn Syaddad ibn Amr al-Azdari. (tt). Sunan Abi Dawud. Beirut: AlMaktabah Al-'Asriyah.

As-Syafi'i, Ahmad ibn 'Ali ibn Hajar Abu Fadl al-Asqolani (1957). Fathul Baari. Beirut: Daar Ma'rifah.

As-Syami, Muhammad ibn Yusuf asShalihi. (1993). Subulul Huda wa Rasyad fi Sirah Khairil 'Ibad wa Zikri Fadailihi wa 'Alami Nubuwwatihi wa Af 'Alihi wa Ahwalihi fil Mabdai wal Ma'ad. Beirut: Dar al-Kutub al-'Ilmiyyah. jilid. VIII.

At-Tabari, Muhammad ibn Jarr ibn Yazid ibn Kasir ibn Ghalib alAmali, Abu Ja'far (1966). Tarikh at-Tabari Tarikhul Rusul wal Muluk, Beirut: Dar al-Turas.

Tafsir, Ahmad. (1992). Ilmu Pendidikan dalam Perspektif Islam. Bandung: Remaja Rosdakarya.

Tim Penyusun Departemen Pendidikan Nasional. (2008). Kamus Besar Bahasa Indonesia. Jakarta: Gramedia Pustaka Utama. 
INTIQAD: JURNAL AGAMA DAN PENDIDIKAN ISLAM

ISSN 1979-9950 (print) || ISSN 2598-0033 (online), http://jurnal.umsu.ac.id/index.php/intiqad DOI: 10.30596/intiqad.v12i2.5197

Vol. 12, No. 2 (December 2020)

Al-Usaimin, Muhammad ibn Shalih.

(2003). Kitaabul 'Ilmi. Mesir: Daar

Bashirah al-Iskandariah.

al-Waqidi, Muhammad ibn Umar ibn al-

Waqid as-Sahmi al-Aslami Abu

Abdillah. (1989). al-Maghazi.

Beirut: Dar al-‘Alami. 